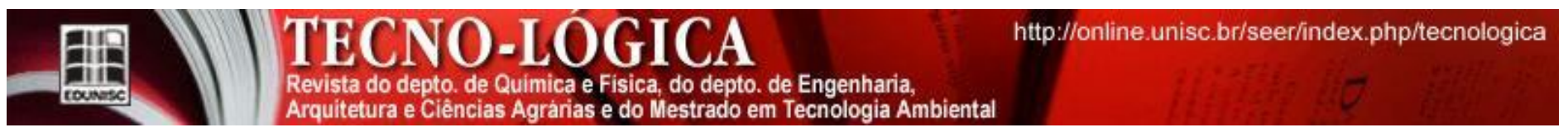

\title{
DEGRADAÇÃO DE ÓLEOS LUBRIFICANTES EM MOTORES ESTACIONÁRIOS MOVIDOS A BIOGAS
}

\author{
Djéssica Brum, Mauricio Ferreira da Rosa, Cleber Antonio Lindino*
}

Laboratório de Estudos em Química Analítica Limpa - LEQAL, Grupo Interdisciplinar de Pesquisas em Fotoquímica e Eletroquímica Ambiental - GIPEFEA, Centro de Engenharias e Ciências Exatas, Universidade Estadual do Oeste do Paraná, 85903-000 Toledo PR, Brasil.

*E-mail: lindino99@gmail.com

\section{RESUMO}

Com o crescente interesse do uso de biogás como fonte de energia elétrica por meio de motores ciclo Otto, as condições de trabalho destes motores se tornam relevantes para maior eficiência de conversão energética e maior tempo de uso. A utilização correta de óleos lubrificantes permite ampliar a quantidade de horas motor, sem necessidade de troca. Avaliar a qualidade e a degradação dos óleos lubrificantes neste sistema torna-se uma premissa importante, uma vez que o óleo degradado diminui a capacidade de proteção nas peças móveis do motor e aumenta o superaquecimento do sistema. A contaminação por agentes externos eleva a chance do desenvolvimento de borras e aumentando a corrosão de peças. Este trabalho realizou o controle de qualidade de óleos lubrificantes em motores estacionários movidos a biogás. Os óleos foram analisados por espectrofotometria na região do infravermelho, na qual foram verificadas as bandas de oxidação, presença de água, fuligem, nitratos e sulfato, sendo determinada também a acidez total do óleo lubrificante, de acordo com a norma ASTM D4739, preconizada pela Resolução ANP n 10/2000. O principal problema encontrado foi a quantidade de água presente nos motores, acima do limite de $0,03 \%$, indicando algum problema de vazamento/contaminação no motor. Os testes controlados com diferentes gases apresentaram pouca variação em relação à comparação com ar, ao controle utilizado e ao gás $\mathrm{N}_{2}$, sendo que os principais parâmetros afetados foram a oxidação e a acidez, pois os outros parâmetros não apresentaram diferenças significativas entre si.

Palavras-chave: Estabilidade. Contaminação. Energia da biomassa.

\section{Introdução}

Informações consolidadas referentes ao ano de 2015 indicam que a matriz energética mundial ainda se concentra no uso do petróleo $(32,9 \%)$, carvão $(29,2 \%)$ e gás $(23,8 \%)$ e as fontes consideradas renováveis oscilam em torno de 6,7 \% [1]. No Brasil, a matriz energética referente aos renováveis situa-se em 41,2\% sendo que, na geração de energia elétrica, $69,1 \%$ provém de fontes renováveis, em grande parte capitaneada pelo sistema hídrico de geração $(58,4 \%)$. Já as fontes envolvendo a biomassa, somam aproximadamente $10,5 \%$ [2].

Em relação à biomassa, a geração de biogás para uso em eletricidade corresponde somente a $0,1 \%$ da matriz, mostrando que este sistema é muito estudado na academia, mas pouco aplicado no setor produtivo. Contudo, a possibilidade de uso do biogás como fonte de eletricidade a partir de motores estacionários tipo Otto é bastante alta.

Aterros sanitários, dejetos de suínos e resíduos orgânicos sólidos de origem urbana podem fornecer matéria-prima em grande quantidade para a obtenção de biogás, gerando eletricidade e diminuindo a necessidade de se utilizar outras fontes mais poluidoras, como as termoelétricas. Além disso, esta tecnologia proporciona um ganho ambiental enorme, pois diminui a quantidade de efluentes poluidores. $\mathrm{O}$ aproveitamento dos resíduos para fins energéticos está previsto, inclusive, no Plano Nacional de Resíduos Sólidos, Lei 12.305/2010 [3].

A utilização de biogás em motores de ciclo Diesel é o mais apropriado, pela sua maior robustez e menor custo para a mesma potência [4-5]. Esse avanço tecnológico no uso de motores a biogás deve-se, em grande parte, ao aumento do preço do petróleo, à crescente preocupação ambiental e ao esgotamento das reservas de petróleo bruto [6].

Com o desenvolvimento e aplicação de motores movidos a biogás, cresce a importância de óleos lubrificantes que possam apresentar eficiência e tempo de vida prolongado [7]. Assim, metodologias para o controle da qualidade desses óleos são extremamente importantes determinando seu processo de degradação em relação ao tempo, em horas, em que o motor é utilizado [8].

O lubrificante tem a finalidade de evitar o sobreaquecimento e o desgaste do motor. As formulações são geralmente constituídas de vários componentes que contém aditivos para melhorar o 
desempenho específico de cada motor. Embora lubrificantes constituídos por óleos minerais sejam largamente utilizados para uma variedade de propósitos, eles são pouco biodegradáveis e, com frequência, tóxicos. Portanto, eles podem ter um forte impacto sobre os seres vivos se atingirem o ambiente.

$\mathrm{Na}$ literatura, ao analisar óleos usados em motores, identificou-se a degradação e a contaminação como principais causas de prejuízo à eficiência do óleo lubrificante [9]. Snook estabeleceu um programa básico de ensaios de óleos de motores e descreveu os procedimentos em laboratório, bem como os meios e as causas de contaminação e degradação, correlacionando os contaminantes com os prováveis defeitos das máquinas e seus pontos de origem [9].

As principais causas da degradação dos óleos são a contaminação por água (externa ou produzida pela combustão), a alimentação excessiva de combustível, a refrigeração inadequada, a poeira, bem como contaminantes presentes no combustível [9].

A degradação é o processo que reduz a capacidade do óleo de cumprir as funções para o qual foi dimensionado, isto é, lubrificar, proteger, limpar, refrigerar e vedar. Ela é originada pela alteração de suas propriedades físicas e químicas, devido às diferentes condições em que é submetido o óleo dentro do motor, sofrendo com altas temperaturas, grandes velocidades de cisalhamento, materiais corrosivos, contaminações, envelhecimento, etc. [10].

Para avaliar a degradação do óleo lubrificante, os parâmetros analisados são a aparência (fuligem), viscosidade, índice de basicidade total (TBN), índice de acidez total (TAN), oxidação, nitração, sulfonação, ponto de fulgor, densidade relativa e corrosão em lâmina de cobre [10].

O índice de acidez total do óleo (TAN) é a medida de ambos os ácidos orgânicos e ácidos inorgânicos fortes presentes no óleo, assim como produtos de degradação. O TAN não é geralmente associado aos lubrificantes do cárter do motor a menos que sejam severamente contaminados. Uma exceção pode ser os lubrificantes de cárter de motores a gás. Neste caso, o TAN pode esgotar muito rapidamente e temperaturas elevadas de operação podem gerar altos níveis de ácidos orgânicos fracos e o aumento na acidez do óleo pode estar ligado à contaminação de água.

Especificamente para motores estacionários a biogás, não há amplos estudos envolvendo o processo de degradação do óleo lubrificante e a estimativa do tempo de vida do óleo [10], mas nestes, a cada amostragem, havia a reposição de óleo novo no motor, que mascara os prováveis efeitos da degradação causada pelo biogás não purificado.

Ao realizar o acompanhamento da qualidade do óleo lubrificante com o tempo, constatando-se os processos de degradação e o consequente desgaste de peças em motores movidos ao biogás, determina-se corretamente o tempo de uso do óleo e o cronograma de troca pelo cliente.
Considerando o exposto, o presente trabalho teve como objetivos simular a influência de gases presentes no biogás no processo de degradação de óleo lubrificante e determinar o índice de degradação do óleo lubrificante utilizado em dois motores movidos a biogás por meio da espectroscopia na região do infravermelho, para determinação dos parâmetros de oxidação, teor de água, nitração, sulfonação e fuligem e o índice de acidez total (TAN), por meio da titulação ácido-base.

\section{Materiais e métodos}

Todos os reagentes químicos utilizados foram de pureza grau para análise. A água utilizada para o preparo de soluções padrão ou diluições de amostras foi destilada e purificada por osmose

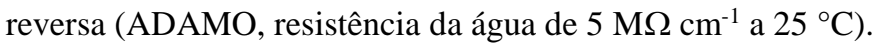

As amostras de óleos lubrificantes foram obtidas de dois motores estacionários tipo Otto Diesel, modificados para biogás, desenvolvidos pela empresa Biogás Motores Estacionários de Toledo, denominados motor A (Mercedes Benz OM 355/5, 140 kVA, $1800 \mathrm{rpm}$ ) e motor B (MWM D-229/6, 60 kVA, $1800 \mathrm{rpm}$ ) (Figura 1), sendo que esses motores foram instalados em duas propriedades rurais na Região Oeste do Paraná, que utilizam biodigestores modelo canadense, com dejetos de suínos como matéria prima e purificação do biogás realizada com injeção de oxigênio e secador (Figura 2).

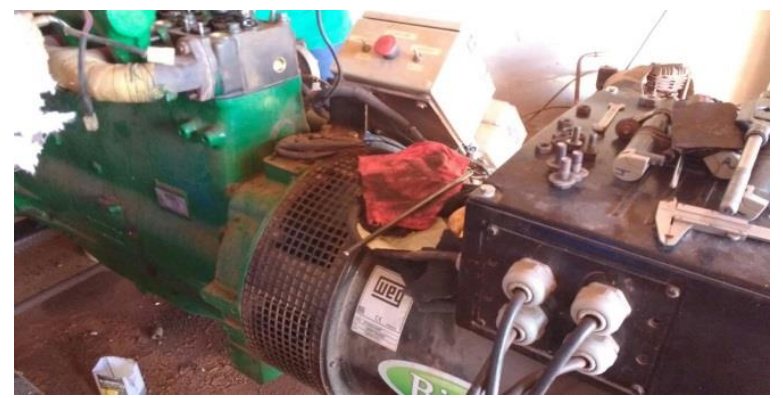

Figura 1. Motor estacionário utilizado para o sistema do biodigestor na propriedade B

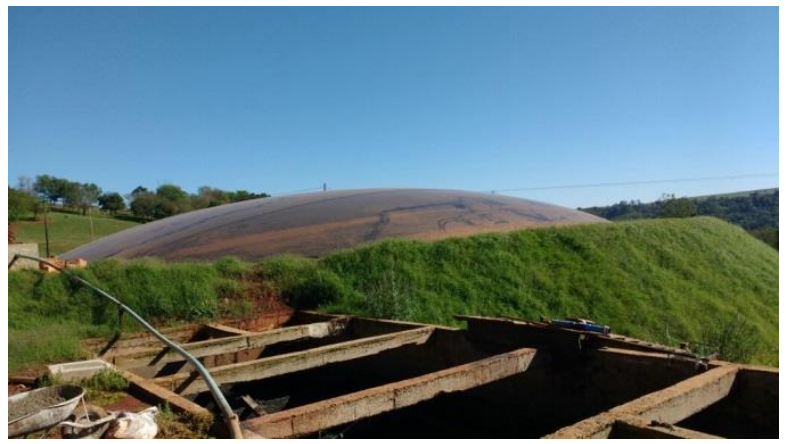

Figura 2. Biodigestor modelo canadense utilizado na propriedade B. 
As amostras dos óleos $(200 \mathrm{~mL})$ dos motores foram coletadas durante as trocas periódicas de manutenção (entre 300 e 400 h), em recipiente de plástico de polietileno tereftalato, fechado e lacrado e levado até o laboratório para análise, anotando-se a quantidade de horas/motor e o funcionamento diário em horas. Durante a amostragem, evitou-se coletar o fluxo inicial e final do óleo, para esquivar-se das impurezas presentes na superfície do lubrificante ou no fundo do cárter, bem como também se evitou succionar borras.

O óleo lubrificante utilizado nos motores estacionários foi o 15W40 APICF/CF2 turbo diesel das marcas Texaco $^{\circledR}$ ou Ipiranga ${ }^{\circledR}$, utilizados também como referências ou controles para comparação.

As amostras, em duplicata, foram analisadas por espectrofotometria na região do infravermelho com transformada de Fourier (FT-IR) em equipamento PerkinElmer Frontier, com kit de análise de óleos, de acordo com a norma ASTM E2412-04 [10], verificando-se as bandas de oxidação, fuligem, nitratos, presença de água e sulfato que indiquem degradação e contaminação do óleo devido aos gases inseridos no motor. $\mathrm{O}$ intervalo do número de onda medido ocorreu entre 4000 a $550 \mathrm{~cm}^{-1}$, com resolução de $8 \mathrm{~cm}^{-1}$ e oitos varreduras sucessivas em cada medida, com célula de $\mathrm{ZnSe}$ e caminho óptico de $0,1 \mathrm{~mm}$.

Também foi avaliada a acidez total do óleo lubrificante, em duplicata, de acordo com a norma ASTM D4739, preconizada pela Resolução ANP no 10/2007 [12]. O método consiste em pesar dois gramas da amostra de óleo lubrificante, adicionar $25 \mathrm{~mL}$ de uma solução de etanol e éter etílico (2:1) e titular com hidróxido de potássio $0,1 \mathrm{~mol} \mathrm{~L}^{-1}$, padronizado com hidrogenoftalato de potássio, e indicador fenolftaleína. A bureta utilizada (erro de \pm $0,05 \mathrm{~mL}$ ) foi calibrada de um em um $\mathrm{mL}$ e foi construído um gráfico de correção. Neste estudo não se mediu a viscosidade do óleo.

Os testes de estabilidade para gases na simulação do motor estacionário foram realizados com o sistema apresentado na Figura 3. Os gases foram escolhidos devido à possibilidade de estarem em contato com o óleo lubrificante no motor estacionário.

Em um balão de volume de $200 \mathrm{~mL}$ de três bocas esmerilhadas acoplou-se uma entrada para injeção dos gases em estudo, sendo ar comum (por meio de uma bomba de aquário), $\mathrm{CO}_{2}$ (Linde ${ }^{\circledR}$ 99,999\%), $\mathrm{N}_{2}$ (Linde $\left.^{\circledR} 99,999 \%\right), \mathrm{CH}_{4}\left(\mathrm{AGA}^{\circledR} 99,5 \%\right.$ ) e $\mathrm{H}_{2} \mathrm{~S}$ gerado a partir da reação de sulfeto ferroso (FeS) e ácido clorídrico, de acordo com a Equação 1.

$$
\mathrm{FeS}_{(s)}+2 \mathrm{HCl}_{(l)} \leftrightharpoons \mathrm{H}_{2} \mathrm{~S}_{(g)}+\mathrm{Fe}^{3+}{ }_{(a q)}+\mathrm{Cl}^{-}{ }_{(a q)}
$$

Em outra boca esmerilhada inseriu-se um termômetro Incoterm, com resolução de $\pm 1,0^{\circ} \mathrm{C}$ e acoplou-se à boca central uma coluna de refluxo acoplado à rede de agua. Após o óleo lubrificante atingir a temperatura entre $145-150{ }^{\circ} \mathrm{C}$, injetaram-se no interior do óleo os gases pelo período de 6 horas. Sendo que, ao final do processo, esperou-se o abaixamento da temperatura às condições ambiente e fez-se a leitura no espectrofotômetro na região do infravermelho, bem como procedeu-se às titulações para medida da acidez.

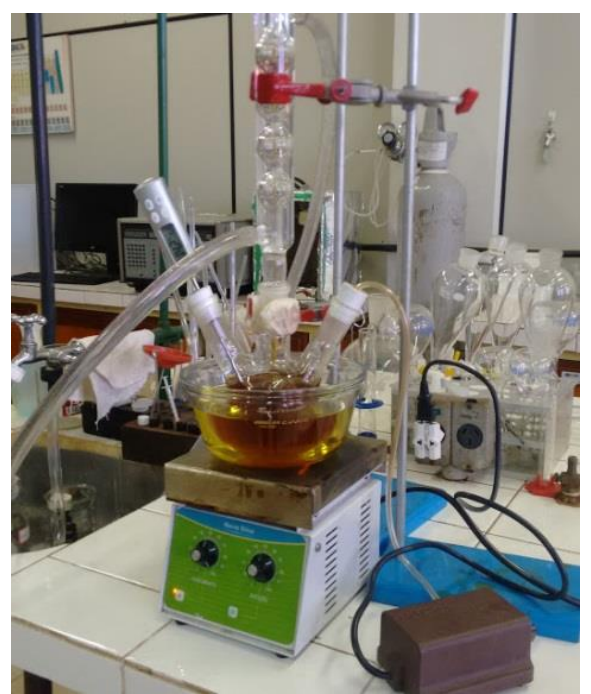

Figura 3. Esquema de montagem para teste de estabilidade com gases.

Para limpeza dos materiais e repetitividade dos resultados utilizou-se solvente heptano com pureza $99 \%$, da marca NEON ${ }^{\circledR}$.

\section{Resultados e discussões}

A Tabela 1 apresenta os resultados para os testes com gases em reator. A amostra de óleo (controle) de óleo lubrificante foi obtida a partir de frasco lacrado.

Tabela 1. Resultados obtidos para testes com gases em reator.

\begin{tabular}{ccccccc}
\hline Parâmetro & Controle & $\mathrm{Ar}$ & $\mathrm{CO}_{2}$ & $\mathrm{~N}_{2}$ & $\mathrm{CH}_{4}$ & $\mathrm{H}_{2} \mathrm{~S}$ \\
\hline Água (\%) & 0,14 & 0,12 & 0,12 & 0,11 & 0,12 & 0,11 \\
Oxidação $\left(\mathrm{A} \mathrm{cm}^{-1}\right)$ & 7,07 & $\begin{array}{c}11,4 \\
3\end{array}$ & 7,52 & 7,18 & 8,58 & 3,95 \\
Nitração $\left(\mathrm{A} \mathrm{cm}^{-1}\right)$ & 4,88 & 6,27 & 5,15 & 4,98 & 5,18 & 3,86 \\
& & 15,7 & 13,62 & 13,1 & 13,6 & 13,2 \\
Sulfonação $\left(\mathrm{A} \mathrm{cm}^{-1}\right)$ & 12,58 & 2 & & 0 & 9 \\
Fuligem & 0,24 & 0,24 & 0,24 & 0,24 & 0,24 & 0,24 \\
& & 5,76 & 4,26 & 1,98 & 8,27 & 3,12 \\
Acidez $\left(\mathrm{mg} \mathrm{g}^{-1}\right)$ & 4,38 & & & & & \\
\hline
\end{tabular}

Observa-se nos testes em reator que os valores para a quantidade de água foram próximos, havendo pouca influência do tipo de gás utilizado. 
Em estudos de campo, a quantidade de água que possa ter se acumulado no motor em repouso (desligado) pode ser volatilizada ao retornar seu funcionamento e atingir altas temperaturas, o que justifica o menor valor de porcentagem de água obtido nos testes no reator à alta temperatura. Importante ressaltar que no processo de combustão de substancias orgânicas gera-se água como um dos produtos e, se o motor estiver à temperatura normal de funcionamento, a maior parte da água se mantém sob a forma vaporizada e acaba saindo do cilindro através do sistema de escape. No entanto, o vapor de água presente nos gases de blow-by ${ }^{l}$ passa para dentro do cárter que está relativamente mais frio e condensado. Esta água pode estabelecerse em várias partes do mecanismo de motor e causar oxidação ou pode misturar-se com o lubrificante e formar borras ou alterar suas características [5].

Há também a possibilidade de as moléculas de água reagirem com os aditivos presentes no óleo lubrificante, aditivos estes que podem variar de fabricante para fabricante e que podem alterar os parâmetros e, por isso, é importante a comparação das amostras de campo com amostras referência ou controle do mesmo óleo.

O teor de fuligem permaneceu constante para todos os gases estudados, indicando a mesma quantidade de carbono insolúvel em suspensão no óleo, resultante de combustão incompleta.

Em relação ao parâmetro oxidação, a injeção de gás $\mathrm{N}_{2}$ não aumenta significativamente o seu valor $(+1,5 \%)$ em comparação com o controle, devido a sua relativa inércia química nestas condições e sua pureza. $\mathrm{O} \mathrm{CO}_{2}$ provoca um aumento de 6,4 $\%$, indicando um pequeno efeito neste parâmetro. $\mathrm{O}$ gás metano e o ar aumentam a oxidação do óleo.

Observou-se também que o $\mathrm{CO}_{2}$, um gás recorrente em motores de biodigestores movidos a biogás, não causa alterações significativas nos parâmetros estudados para o óleo, ou seja, sua presença no sistema não deve afetar a qualidade do óleo.

A oxidação é um parâmetro importante na degradação dos lubrificantes [13-14], contudo, os óleos lubrificantes são misturas multicomponentes, por isso, a complexidade de sua degradação tem frustrado a resolução do controle desta reação fundamental (oxidação) nos estudos experimentais [15]. Há também a dificuldade em reproduzir teste de oxidação e corrosão devido às reações paralelas dos aditivos nos óleos, como degradação ou volatilização [13].

Os produtos provenientes da degradação térmica de diversos óleos lubrificantes podem ser determinados por cromatografia a gás e espectrometria de massas, sendo verificado que há fragmentação das cadeias carbônicas, de 20 a 25 carbonos no óleo para C13 a C14 em óleos degradados, bem como o surgimento de compostos carbônicos oxigenados, devido à reação com o oxigênio [16].

Os óleos lubrificantes contêm em sua composição diversos aditivos, tais como modificadores de fricção, agentes antidesgaste, inibidores de ferrugem e de corrosão, antioxidantes, detergentes e dispersantes, que variam de fabricante para fabricante e, muitas vezes, são sigilos de patente, tornando difícil inferir sobre sua influência na alteração dos parâmetros.

Entre estes aditivos, incluem-se compostos organometálicos de níquel como agente antidesgaste, complexos orgânicos de chumbo como aditivo de extrema pressão e dialquiltiofosfato de zinco (ZnDDP) como inibidor de corrosão, antioxidante e antidesgaste [17-18].

Óleos lubrificantes analisados antes e depois de seu uso mostraram que os principais componentes presentes no óleo novo são zinco, cálcio, magnésio, fósforo, com traços de ferro, alumínio e silício. Nos óleos usados na análise encontrou-se também cobre, molibdênio, chumbo, estanho e níquel, com aumento no teor de ferro, zinco, fósforo e magnésio [10].

Outros autores [19] encontraram em amostra de óleo não utilizado metais como molibdênio $\left(9,4 \mathrm{mg} \mathrm{L}^{-1}\right)$, zinco $(812,0 \mathrm{mg}$ $\left.\mathrm{L}^{-1}\right)$, ferro $\left(54,6 \mathrm{mg} \mathrm{L}^{-1}\right)$ entre outros, indicando a variabilidade de metais que podem ser encontrados em óleos lubrificantes.

Um modificador de fricção muito utilizado é o dissulfeto de molibdênio $\left(\mathrm{MoS}_{2}\right)$, que também é um catalisador utilizado em reações orgânicas [20-21]. Assim, é possível que diversas reações no óleo possam ocorrer durante o processo em alta temperatura, catalisadas por $\mathrm{MoS}_{2}$, na presença dos diferentes gases, que provoquem alterações nos parâmetros estudados.

O processo de nitração se desenvolve quando ocorre a combinação do nitrogênio e do oxigênio do ar em condições de altas temperaturas e pressões do motor. Relaciona-se diretamente aos fenômenos decorrentes de oxidação do produto, sendo que a incidência maior ocorre em motores movidos a gás natural.

Comparados com o controle, os espectros do FT-IR (Figuras 4 e 5) para os óleos lubrificantes são similares para todas as amostras, com exceção para os testes realizados com os gases $\mathrm{CO}_{2}$ e $\mathrm{H}_{2} \mathrm{~S}$, com deslocamentos hipsocrômicos ou batocrômicos ou efeito hipercrômico de bandas do espectro [22-24].

Com $\mathrm{CO}_{2}$ observou-se o surgimento de banda em 2330 $\mathrm{cm}^{-1}$ (Figura 4) atribuída ao estiramento antissimétrico $\mathrm{O}=\mathrm{C}=\mathrm{O}, \mathrm{o}$ que pode indicar a solubilização parcial de $\mathrm{CO}_{2}$ no óleo, como pode ser observado em trabalhos na literatura [25-27]. Observamse ainda as bandas em $2900-3000 \mathrm{~cm}^{-1}$ atribuídas ao estiramento simétrico e assimétrico de $\mathrm{C}_{\mathrm{sp} 3}-\mathrm{H}, 1710 \mathrm{~cm}^{-1}$ atribuída ao

\footnotetext{
${ }^{1}$ Blow-by é o nome dado em inglês ao vazamento que ocorre dos gases queimados para o cárter, entre pistão, seus anéis e o cilindro.
} 
estiramento $\mathrm{C}=\mathrm{O}$ e 1490 e $1450 \mathrm{~cm}^{-1}$ atribuídas à vibração angular no plano (bending) de $\mathrm{CH}_{3}$ e $\mathrm{CH}_{2}$, respectivamente.

Com $\mathrm{H}_{2} \mathrm{~S}$, observou-se o desaparecimento da banda (Figura 5) em $1710 \mathrm{~cm}^{-1}$ e das bandas em $976 \mathrm{~cm}^{-1}$ e $656 \mathrm{~cm}^{-1}$, referentes às vibrações das ligações $\mathrm{C}=\mathrm{C}$ (deformação angular de alceno trans substituído) e $\mathrm{C}=\mathrm{C}$ (deformação angular de alceno cis substituído), respectivamente. Isto sugere reações dos componentes do óleo lubrificante com o sulfeto, diminuindo as saturações de determinados grupos funcionais.

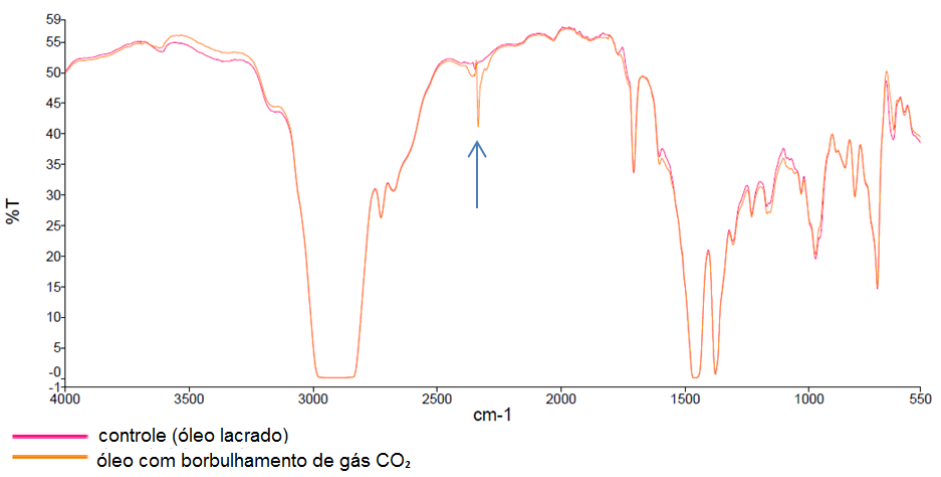

Figura 4. Comparação dos espectros de FTIR para amostra de óleo lubrificante controle (sem injeção de gás) e amostra de óleo lubrificante com injeção de gás $\mathrm{CO}_{2}$.

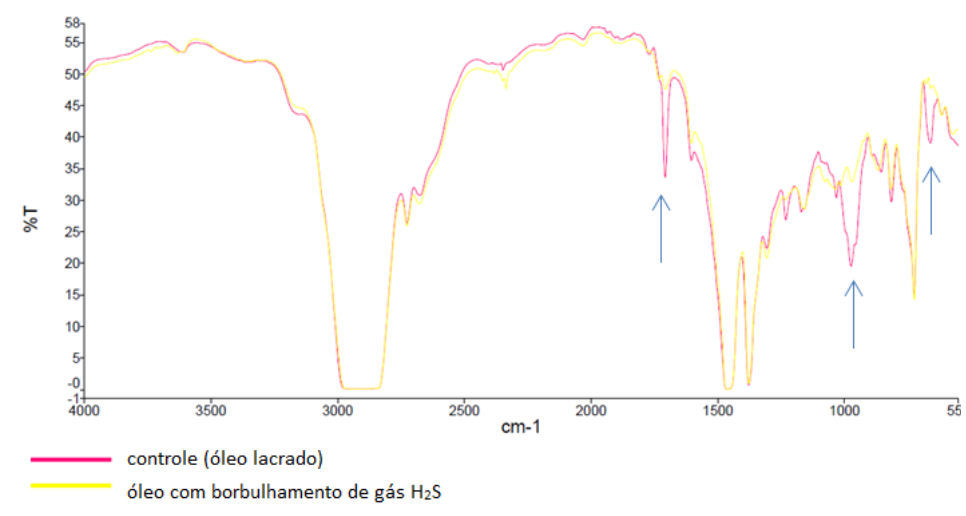

Figura 5. Comparação dos espectros de FTIR para amostra de óleo lubrificante controle (sem injeção de gás) e amostra de óleo lubrificante com injeção de gás $\mathrm{H}_{2} \mathrm{~S}$.

Para o índice de acidez, observou-se aumento para o teste com gás metano de $88,8 \%$ e para o teste com o ar o aumento na acidez foi de $31,5 \%$. Observou-se também diminuição do índice para o teste com nitrogênio $(-54,8 \%)$ e para o $\mathrm{H}_{2} \mathrm{~S}$ (-

\footnotetext{
${ }^{2}$ Os autores se basearam em normas alemãs: Allianz Versicherungs AG (publ.). Bewertung des Gebrauchtölzustands von stationären Gasmotoren; Allianz Report für Risiko und Sicherheit: Allianz Versicherungs AG, Germany, 2004 e Stationäre Gasmotoren-Beurteilung des Gebrauchtölzustands und Limitwerte; Oelcheck GmbH: Brannenburg, Germany, 2002.
}

$28,8 \%$ ). Neste caso, possivelmente o gás sulfídrico pode ter reagido com algum dos aditivos metálicos presentes na composição dos óleos minerais, catalisando a reação e diminuindo, assim, o valor obtido. $\mathrm{O}_{2} \mathrm{~S}$ é um agente redutor, que altera os valores de oxidação, nitração e acidez, devido a sua capacidade de reduzir grupos ácidos presentes no meio.

Analisando os espectros, comparados ao $\mathrm{N}_{2}$, observa-se o desaparecimento dos picos indicados nas respectivas Figuras, relacionados, possivelmente, com a formação de compostos inorgânicos que não absorvem na região do infravermelho e, por isso, não foram detectados. Embora a fuligem tenha valores semelhantes, a combustão incompleta leva a formação de grupos oxidados e, assim, ao aumento da acidez. Dessa forma, pode-se justificar o baixo valor de acidez para $\mathrm{N}_{2}$.

A Tabela 2 apresenta os resultados obtidos no período de três meses do óleo referência (controle) utilizado como lubrificante nos motores estudados, comparando-se com os resultados da literatura [10,29]. Nota-se que o óleo utilizado neste trabalho como referência apresenta parâmetros com valores similares aos encontrados na referência [10], indicando óleo de qualidade. Ressalta-se que mesmo um óleo novo, sem uso, pode apresentar acidez devido aos aditivos em sua composição, assim como outros parâmetros como oxidação e nitração.

Tabela 2. Parâmetros obtidos para o óleo referência (controle), medidos ao longo de três meses, comparando-se com os valores máximos descritos na literatura.

\begin{tabular}{|c|c|c|c|c|c|}
\hline Parâmetro & 1 & 2 & 3 & $\begin{array}{c}\text { Literatura } \\
{[28]^{2}}\end{array}$ & $\begin{array}{c}\text { Literatura } \\
{[10]}\end{array}$ \\
\hline Água (\%) & 0,17 & 0,31 & 0,30 & 0,03 & - \\
\hline $\left.\begin{array}{c}\text { Oxidação }\left(\mathrm{A} \mathrm{cm}^{-}\right. \\
1\end{array}\right)$ & 6,97 & 7,14 & 6,87 & 20 & 8 \\
\hline$\underset{1}{\operatorname{Nitração~}\left(\mathrm{A} \mathrm{cm}^{-}\right.}$ & 4,97 & 5,06 & 4,95 & 20 & 4 \\
\hline $\begin{array}{c}\text { Sulfonação (A } \\
\left.\mathrm{cm}^{-1}\right)\end{array}$ & 12,30 & 11,88 & 11,78 & 25 & 14 \\
\hline Fuligem & 0,24 & 0,24 & 0,25 & - & 0,00 \\
\hline Acidez $\left(\mathrm{mg} \mathrm{g}^{-1}\right)$ & 3,26 & 4,26 & 4,26 & $* 3$ & 9,759 \\
\hline
\end{tabular}

Para o óleo referência também se observa a incorporação de água presente na atmosfera na amostra ao longo do tempo (exposição do óleo ao ambiente), sendo que o mesmo não ocorre com outros parâmetros, com exceção da acidez, na qual, neste caso, pode haver uma correlação com a presença de água, havendo

\footnotetext{
3 *as normas estabelecem que o valor máximo de acidez não deve exceder o valor encontrado no óleo controle $+2,5 \mathrm{mg} \mathrm{g}^{-1}$.
} 
aumento de 30,7\% na acidez após três meses, apesar de atender ao valor máximo disposto nas normas alemãs.

Para os testes em campo, as Tabelas 3 e 4 apresentam os resultados das amostras coletadas nos motores $\mathrm{A}$ e $\mathrm{B}$, incluindo a hora/motor de cada coleta.

Os resultados mostram que os teores para água são excedidos, devido principalmente à condensação em algumas partes do motor, após resfriamento e exposição às condições climáticas no local onde está o equipamento, devido ao aumento na umidade relativa do ar ou abaixamento da temperatura na madrugada.

A água pode deslocar o óleo em superfícies de contato, reduzindo a quantidade de lubrificação e ativando as superfícies que podem agir como catalisadores para a degradação do óleo. A água é um contaminante crítico em muitos sistemas de lubrificação de óleo ocasionando falhas em diversos mecanismos.

Tabela 3. Dados obtidos para óleo coletado no motor A.

\begin{tabular}{|c|c|c|c|c|c|}
\hline Parâmetro & Coleta 1 & Coleta 2 & $\begin{array}{c}\text { Coleta } \\
3\end{array}$ & $\begin{array}{c}\text { Coleta } \\
4\end{array}$ & $\begin{array}{c}\text { Literatura } \\
\text { [28] }\end{array}$ \\
\hline Água (\%) & 0,20 & 0,49 & 0,38 & 0,29 & 0,03 \\
\hline $\begin{array}{c}\text { Oxidação } \\
1)\end{array}$ & 7,93 & 8,44 & 8,16 & 8,51 & 20 \\
\hline Nitração $\left(\mathrm{A} \mathrm{cm}^{-1}\right)$ & 3,98 & 5,15 & 5,17 & 5,19 & 20 \\
\hline $\begin{array}{l}\text { Sulfonação (A } \\
\left.\mathrm{cm}^{-1}\right)\end{array}$ & 26,21 & 29,41 & 20,15 & 26,34 & 25 \\
\hline Fuligem & 0,28 & 0,24 & 0,25 & 0,28 & - \\
\hline Acidez $\left(\mathrm{mg} \mathrm{g}^{-1}\right)$ & 8,64 & 9,27 & 3,49 & 3,74 & $* *$ \\
\hline Hora/motor & 308 & 310 & 300 & 320 & - \\
\hline
\end{tabular}

Tabela 4. Dados para óleo coletado no motor B.

\begin{tabular}{cccccc}
\hline Parâmetro & 1 & 2 & 3 & 4 & $\begin{array}{c}\text { Literatura } \\
{[28]}\end{array}$ \\
\hline Água (\%) & 0,23 & 0,19 & 0,23 & 0,20 & 0,03 \\
Oxidação $\left(\mathrm{A} \mathrm{cm}^{-1}\right)$ & 6,77 & 7,37 & 8,84 & 9,34 & 20 \\
Nitração $\left(\mathrm{A} \mathrm{cm}^{-1}\right)$ & 5,80 & 5,71 & 7,05 & 6,34 & 20 \\
Sulfonação $\left(\mathrm{A} \mathrm{cm}^{-1}\right)$ & 13,05 & 14,48 & 16,83 & 18,23 & 25 \\
Fuligem & 0,24 & 0,24 & 0,25 & 0,28 & - \\
Acidez $\left(\mathrm{mg} \mathrm{g}^{-1}\right)$ & 6,01 & 6,26 & 3,24 & 3,70 & $* *$ \\
Hora/motor & 300 & 304 & 470 & 501 & - \\
\hline
\end{tabular}

Em relação à acidez, que ultrapassou o limite em alguns resultados, o aumento observado refere-se tanto à formação de ácidos orgânicos e inorgânicos resultantes do processo de degradação do óleo lubrificante pela presença de água em pequenas quantidades no motor, quanto pela inserção de gás sulfídrico, proveniente do biogás gerado no biodigestor e reações com os aditivos presentes nos óleos.

No motor A, o valor de sulfonação é muito mais alto que no motor $\mathrm{B}$, superando o limite da referência, indicando que o processo de purificação no biodigestor que está acoplado ao motor B é mais eficiente na remoção do contaminante $\mathrm{H}_{2} \mathrm{~S}$. Há pouca relação entre os parâmetros avaliados que possam indicar efeitos correlacionados entre eles. Há inúmeras variáveis como a qualidade (composição) do biogás, refletida nas condições dos biodigestores e no sistema de purificação, no tipo de motor, no número de horas/motor ou funcionamento diário e local no qual o motor se encontra (protegido ou não de intempéries).

Algumas tendências puderam ser observadas para os parâmetros determinados no motor $\mathrm{B}$, que possui biodigestor e sistemas de purificação de melhor eficiência e com manejo constante, como a diferença nos resultados entre as coletas. Ao se investigar as variáveis, verificou-se que a diferença entre as coletas pode ser devido à variação na temperatura máxima do ambiente (Figuras 9 a 12).

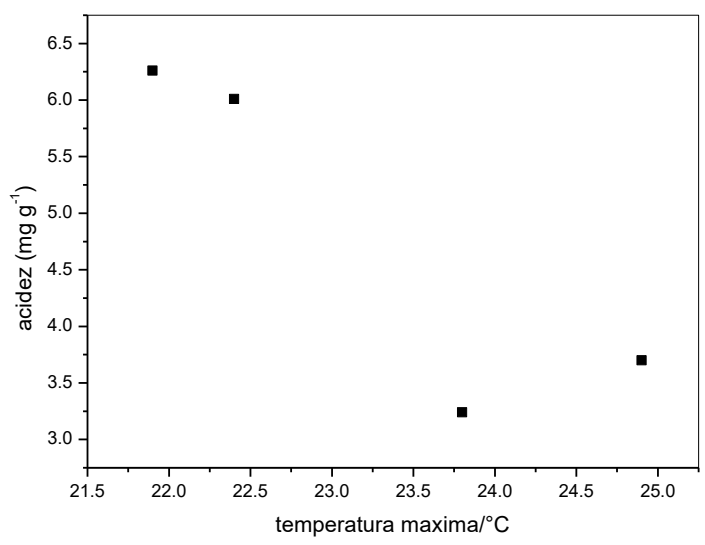

Figura 9. Tendência observada para o parâmetro acidez em relação às temperaturas máximas ambientais para o motor $\mathrm{B}$.

Os parâmetros de sulfonação, nitração e oxidação tendem a aumentar com o aumento da temperatura ambiente, enquanto que o índice de acidez tende a diminuir.

Apesar de serem necessários mais estudos para comprovar e compreender esses fenômenos, existe a possiblidade de que a diferença na temperatura ambiente, em biodigestores sem controle de temperatura, afeta o desenvolvimento das bactérias produtoras de metano, uma vez que o processo da digestão anaeróbia é complexo e envolve pelo menos sete etapas: hidrolise de proteínas, lipídios e carboidratos; fermentação de aminoácidos e açucares; oxidação anaeróbia de ácidos graxos de cadeia longa e álcoois; oxidação anaeróbia de ácidos graxos voláteis; conversão 
de $\mathrm{CO}_{2}$ e $\mathrm{H}_{2}$ em ácido acético; conversão de ácido acético em $\mathrm{CH}_{4}$ e conversão do $\mathrm{H}_{2}$ em $\mathrm{CH}_{4}$ [29].

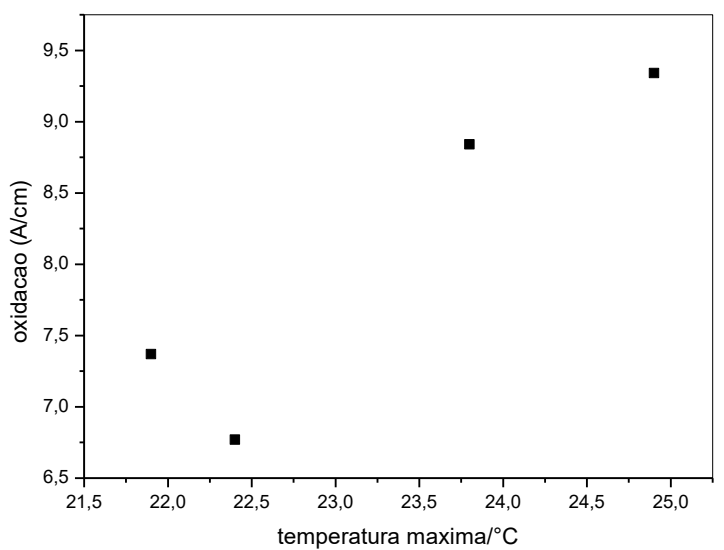

Figura 10. Tendência observada para o parâmetro oxidação em relação às temperaturas máximas ambientais para o motor $\mathrm{B}$.

A alteração na temperatura ambiente pode afetar a temperatura da digestão anaeróbia, envolvendo crescimento termofilico $\left(50\right.$ a $\left.60{ }^{\circ} \mathrm{C}\right)$ ou mesofilico $\left(30-40{ }^{\circ} \mathrm{C}\right)$ das bactérias, que alteram as proporções dos gases componentes do biogás, que podem afetar o óleo lubrificante em seus diversos parâmetros e, consequentemente, sua qualidade [29].

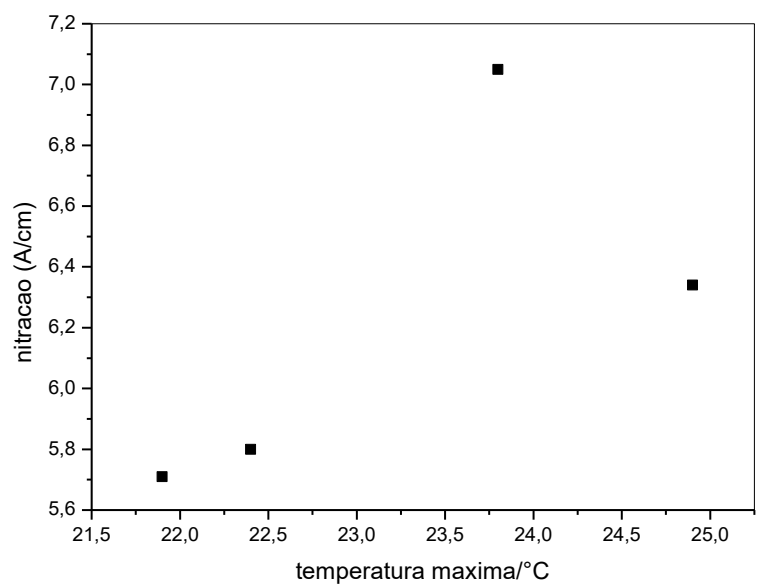

Figura 11. Tendência observada para o parâmetro nitração em relação às temperaturas máximas ambientais para o motor B.

As bactérias sulfato redutoras também estão presentes nos processos anaeróbios e competem com as metanogênicas pelo hidrogênio e pelo acetato para reduzir os sulfatos presentes no meio. Uma vez que os sistemas de purificação dos biodigestores estudados envolvem a injeção de ar (oxigênio) para a oxidação do
$\mathrm{H}_{2} \mathrm{~S}$, este processo pode ser afetado também, alterando novamente a composição do biogás.

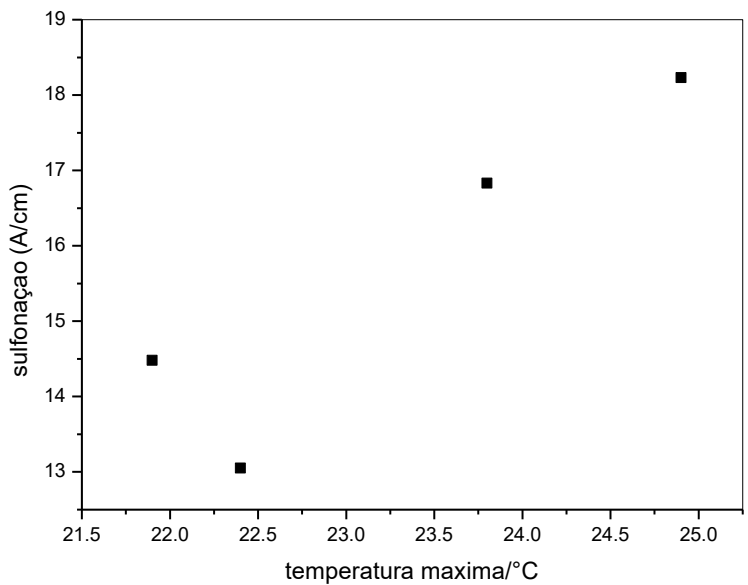

Figura 12. Tendência observada para o parâmetro sulfonação em relação às temperaturas máximas ambientais para o motor B.

A adoção de medidas de controle de qualidade do óleo lubrificante permite estimar seu tempo de vida e a hora/motor para evitar desgastes nas peças que o compõe e diminuir possíveis efeitos corrosivos. Paralelo a isto, a qualidade do biogás inserido no motor deve ser suficiente para que a quantidade de água e sulfetos seja minimizada, para evitar a degradação precoce do óleo lubrificante.

Dados obtidos em amostra não reportada neste trabalho indicaram funcionamento inadequado do sistema de purificação no motor A, com injeção de água no sistema de combustão, pois os índices de água e oxidação foram bastante elevados $(0,82 \%$ e $8,75 \mathrm{~A} / \mathrm{cm}$, respectivamente), com aumento também em material particulado, indicado pelo valor de fuligem $(9,6)$, além da observação da formação de particulado de enxofre elementar no óleo. O enxofre, durante a combustão, combina-se com a água formando o ácido sulfúrico, que corrói peças internas do motor. Isto pode indicar uma relação entre aumento no teor de água e aumento na oxidação do óleo.

Outra discussão importante é quanto ao tempo necessário para troca do óleo (hora/motor). Normalmente, os fabricantes determinam a troca do óleo com 300 horas de funcionamento do motor. Os resultados deste trabalho corroboram com outros apresentados na literatura $[10,30]$ e mostraram que este período pode ser estendido para até $400 \mathrm{~h}$ /motor, sem prejuízo na eficiência do óleo e do motor, verificando-se que a viscosidade do óleo lubrificante permanece constante (em torno de $200 \mathrm{cP}$ ) até 400 horas de uso em temperatura de $210^{\circ} \mathrm{C}$. 


\section{Conclusão}

Este estudo mostrou que o controle de qualidade dos óleos lubrificantes utilizados em motores a biogás é importante para avaliar a degradação do mesmo e os parâmetros estudados indicam a dependência das condições do motor, das horas trabalhadas e do sistema de biodigestor e purificadores do biogás. Os parâmetros de acidez total e oxidação constaram como os parâmetros que mais foram influenciados nos motores.

A presença de água nos óleo indica que pode haver em longo prazo a corrosão das peças ou formação de borras que impeçam o funcionamento correto do motor. A eficiência do motor estacionário está diretamente ligada à qualidade do biogás inserido em seu sistema. Tem-se, assim, que os motores estudados podem trabalhar mais de 300 horas, até a troca do óleo lubrificante, principalmente em sistemas com maior tempo de trabalho por dia.

\section{Agradecimentos}

À Fundação Araucária pela bolsa de Iniciação Científica e à Empresa Biogás Motores Estacionários de Toledo pelo apoio na realização do projeto.

\section{DEGRADATION OF LUBRICANT OILS USED IN STATIONARY ENGINES FUELLED BY BIOGAS}

ABSTRACT: With the growing interest in the use of biogas as a source of electricity through Otto cycle engines, the working conditions of these engines become relevant for greater energy conversion efficiency and longer uptime. The correct use of lubricating oils allows increasing the number of engine hours, without the need of exchange. Assessing the quality and degradation of lubricating oils in this system becomes an important premise, as degraded oil decreases the protective capacity of the moving parts of the engine and increases system overheating. Contamination by external agents increases the chance of the development of lees and increases the corrosion of parts. This work carried out the quality control of lubricating oils in stationary engines driven by biogas. The oils were analyzed by spectrophotometry in the infrared region, in which the oxidation bands, presence of water, soot, nitrates and sulfate were verified. The total acidity of the lubricating oil according to ASTM D4739 was also determined. The main problem was the amount of water present in the engines, above the limit of $0.03 \%$ indicating some problem of leakage/ contamination in the engine. The controlled tests with different gases showed little variation compared to air, the control used and the $\mathrm{N}_{2}$ gas. The main parameters affected were oxidation and acidity, since the other parameters did not present significant differences between them.
Keywords: Stability. Contamination. Biomass Energy.

\section{Referências}

[1] BRITISH PETROLEUM; Energy Statistical Review. 65 ${ }^{\text {a }}$ Edição; British Petroleum; Londres, 2016.

[2] BRASIL. Ministério das Minas e Energia. Resenha Energética Brasileira; Imprensa Oficial; Brasília, 2016.

[3] BRASIL. Lei 12.305 de 02 de agosto de 2010. Institui a Política Nacional de Resíduos Sólidos. Brasília: Diário Oficial da União de 03 de agosto de 2010.

[4] MIHIC, S.; Biogas fuel for internal combustion engines. International Journal of Engineering, Vol. 2, p. 184-187, 2004.

[5] PEREIRA, Flávio Marcos de Melo. Estudo da degradação do óleo lubrificante em motores alimentados com biodiesel B100, 2015. 145f. Dissertação (Programa de Pós-Graduação em Engenharia Mecânica e de Materiais - Mestrado) Universidade Tecnológica Federal do Paraná, Curitiba. 2015.

[6] ARUMUGAM, S.; SRIRAM, G.; ELLAPPAN R.; Bio-lubricant-biodiesel combination of rapeseed oil: An experimental investigation on engine oil tribology, performance, and emissions of variable compression engine. Energy, Vol. 72, p.618-627, 2014.

[7] BELMIRO, P. N.; CARRETEIRO, R. P.; Lubrificantes e Lubrificação Industrial; Ed. Interciência; Rio de Janeiro, 2006.

[8] dos SANTOS JUNIOR, Araci Araújo. Determinação de parâmetros de óleos lubrificantes de motores ciclo Otto e ciclo Diesel através da Espectroscopia no Infravermelho, métodos multivariados e cartas de controle, 2011. 116f. Dissertação (Programa de Pós-Graduação em Química - Mestrado) - Universidade de Brasília, Brasília, 2011.

[9] SNOOK, W.A.; Uma publicação técnica dedicada à escolha e uso de lubrificantes: Análises de óleos usados de motores; Texaco Brasil S.A. Lubrificação; São Paulo, 1968.

[10] BERTINATTO, Rovian. Análise da contaminação e degradação do óleo lubrificante e desgaste de um motor ottolizado alimentado por biogás, 2014. 75f. Dissertação (Programa de Pós-Graduação em Engenharia de Energia na Agricultura - Mestrado) - Universidade Estadual do Oeste do Paraná, Cascavel, 2014

[11] ASTM E2412. Standard Practice for Condition Monitoring of Used Lubricants by Trend Analysis Using Fourier Transform Infrared (FT-IR) Spectrometry, ASTM International, West Conshohocken, PA, 2004.

[12] BRASIL. Agência Nacional do Petróleo, Gás Natural e Biocombustíveis. Resolução $n^{\circ} 10 / 2007$. Estabelece os critérios para concessão do registro dos lubrificantes acabados. DOU 09/03/2007.

[13] KELLER, M. A.; SABA, C. S.; Oxidative stability and degradation mechanism of a cyclotriphosphazene lubricant. Anal. Chem., Vol. 68, n. 19, p. 3489-3492, 1996

[14] NALDU, S. K.; KLAUS, E. E.; DUDA, J. L.; Evaluation of liquid phase oxidation products of ester and mineral oil lubricants. Ind. Eng. Chem. Prod. Res. Dev., Vol. 23, p. 613-619, 1984.

[15] SANTOS, J. C. O.; SOUZA, A. G.; SANTOS, I. M. G.; CONCEIÇÃO, M. M.; SOBRINHO, E. V.; FERNANDES JUNIOR, V. J. T.; Thermoanalytical and rheological characterization of automotive mineral lubricants after thermal degradation, Fuel, Vol. 83, n. 17, p. 2393-2399, 2004. 


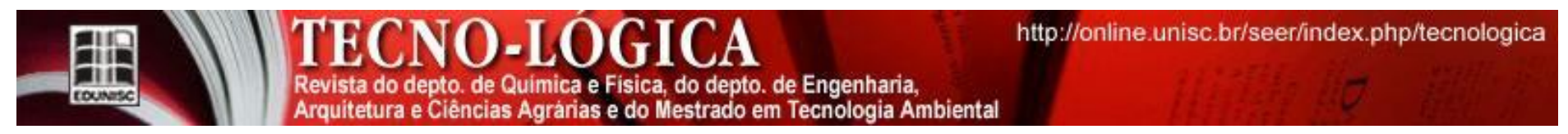

[16] SANTOS, J.C.O.; SOBRINHO, E.V; SOUZA, A.G. de; SANTOS, I.M.G.; Conceição, M.M. da; Estudo da degradação térmica de óleos lubrificantes automotivos por cromatografia gasosa/espectrometria de massa. In: $3^{\circ}$ Congresso Brasileiro de P\&D em Petróleo e Gás, 1998, Salvador, Brasil. Anais...Salvador, 2005.

[17] SINGH, S. K.; AGARWAL, A. K.; SHAMA, M.; Experimental investigations of heavy metal addition in lubricating oil and soot deposition in an EGR operated engine, Applied Thermal Engineering, Vol. 26, p. 259-266, 2006.

[18] SILVEIRA, E.L.C.; COELHO, R. C.; MOITA NETO, J. M.; MOURA, C. V. R.; MOURA, E. M.; Determinação de metais em óleos lubrificantes, provenientes de motores de ônibus urbano, utilizando a FAAS. Química Nova, Vol. 33, n. 9, p. 1863-1867, 2010.

[19] FREITAS, R. V.; DAMASCENO, C. P.; CERQUEIRA. C. P.; PONTES, L. A. M.; Remoção de metais em óleos lubrificantes usados utilizando argila ativada, 2004. In: $2^{\circ}$ Congresso Brasileiro de P\&D em Petróleo e Gás, Rio de Janeiro, Brasil, 2004.

[20] WYPYCH, F.; Dissulfeto de molibdênio, um material multifuncional e surpreendente, Química Nova, Vol. 25, n. 1, p. 83-88, 2002.

[21] PINHO, D. M. M.; SUAREZ, P. A. Z.; A Hidrogenação de Óleos e Gorduras e suas Aplicações Industriais, Rev. Virtual Quim., Vol. 5, n.1, p. 47-62, 2013.

[22] SILVERSTEIN, R.M.; Identificação espectrométrica de compostos orgânicos. 5. ed. Rio de Janeiro: Guanabara Koogan, 1994.

[23] SALA, O. Fundamentos de Espectroscopia Raman e no Infravermelho. 1. ed. São Paulo: UNESP, 1996.

[24] PAVIA, L.D.; LAMPMAN, M.G.; KRIZ, S.G.; VYVYAN, R.J.; Introdução à espectroscopia. São Paulo: Cengage Learning, 2010.

[25] YOKOZEKI, A.; Solubility correlation and phase behaviors of carbon dioxide and lubricant oil mixtures, Applied Energy, Vol. 84, p. 159-175, 2007.

[26] MARCELINO NETO, M. A.; BARBOSA, J. R.; Phase and volumetric behavior of mixtures of carbon dioxide (R-744) and synthetic lubricant oils, Journal of Supercritical Fluids, Vol. 50, p. 6-12, 2009.

[27] HOWLADER, M. S.; FRENCH, W. T.; TOGUIANI, H.; HARTENBOWER, B.; PEARSON, L.; DUBIEN, J.; RAI, N.; Measurement and correlation of solubility of carbon dioxide in triglycerides, Journal Chemistry Thermodynamics, vol. 104, p. 252-260, 2017.

[28] NAEGELE, H.-J.; THOMAS, B.; SCHRADE, C.; LEMMER, A.; OECHSNER, H.; JUNGBLUTH, T.; Influence of maintenance intervals on performance and emissions of a $192 \mathrm{~kW}$ biogas gas Otto CHP unit and results of lubricating oil quality tests - Outcome from a continuous two-year measuring campaign, Energies, n.. 6, p. 2819-2839, 2013.

[29] CCE. Guia Técnico de Biogás. Centro para a Conservação da Energia Algés, Portugal: JE92 Projectos de Marketing LTDA, 2000.

[30] LOPES, E.H.O.; CARVALHO, L.H.; Efeitos do envelhecimento térmico na estrutura química e reologia de um óleo lubrificante mineral. In: $4^{\circ}$ Congresso Brasileiro de P\&D em Petróleo e Gás, 2007. Anais... Campinas, Brasil, 2007. 